\title{
Approach for Cost Determination of Electro-Mechanical Equipment in RoR SHP Projects
}

\author{
Sachin Mishra, Sunil Kumar Singal, Dheeraj Kumar Khatod
}

Alternate Hydro Energy Centre, Indian Institute of Technology Roorkee, Roorkee, India.

Email: rite2sm@gmail.com

Received February $13^{\text {th }}, 2011$; revised March $5^{\text {th }}, 2011$; accepted March $8^{\text {th }}, 2011$.

\begin{abstract}
Electricity is one of the most widely used forms of energy. Being a renewable source of energy small hydropower is considered as an environment-friendly and cheap source of electricity. The installation cost of the small hydropower project depends mainly on two parts-civil works and electromechanical equipment. One of the most important element on the recovery of a small hydro-power plant is the electromechanical equipment (turbine-alternator). The present paper intends to develop a correlation to determine the cost based on the cost influencing parameters as power and head using three different methods, namely; sigma plot method, linest method and logest method. An attempt has also been made to identify the best correlation among the three models closer to the actual cost of electro-mechanical equipment as collected from recently developed projects.
\end{abstract}

Keywords: Small Hydropower Plant, Electro-Mechanical Equipments, Linest, Logest

\section{Introduction}

Energy is the basic requirement for economic development of a country. The growing demand for energy has resulted in a dependency on fossil fuels. The price of fossil fuels and security of energy supply have been a serious concern in India for many decades. India has a large hydro potential in the range of medium and bigger size projects. After independence in 1947, large hydroelectric projects were executed, some of them are still under construction and some are planned for the future. The inherent drawbacks associated with large hydro are large gestation periods, submergence of large areas along with vegetation, and resettlement of the people. Political and environmental implications have made planners to look for alternatives of large hydro. Such alternative could be small hydro. Electricity from small hydro is probably the oldest and reliable renewable energy source. In India, the potential for small hydro has been estimated about 15,000 MW. Out of total 5,415 potential sites, 760 small hydro schemes with a total installed capacity of nearly 2803 MW are in operation and 285 schemes with another 940 MW capacity are under various stages of implementation [1-3].

Small Hydropower Plants (SHPs) have found special importance due to their relatively low administrative and executive costs and a short construction time compared to large power plants. These SHPs are mostly in the run of river (RoR) category using instantaneous diverted flow of river runoff and consists of diversion weir, water conductor system (intake channel, desilting tank, power channel, forebay, penstock), power house and tailrace under civil works as well as electrical and mechanical equipment.

To take investment decision, cost is an important factor. The cost of SHP schemes comprises cost of civil works and electro-mechanical equipment. The cost of civil works can be estimated based on actual quantities of various items as per design drawings, but cost of electro-mechanical equipment, depend on budgetary quotations of the manufactures. Keeping this in view, an attempt has been made to develop a methodology for computation of cost of electro-mechanical equipments in the present study.

\section{Small Hydropower Technology}

Hydro-turbines convert water pressure into mechanical shaft power, which can be used to drive an electricity generator, or other machinery. The power available is pro- 
portional to the product of pressure head and volume flow rate. The general expression for power output from a hydropower scheme is given in Equation (1).

$$
P=\eta \rho g Q h
$$

where, $P$ is the mechanical power produced at the turbine shaft (W), $\eta$ is the hydraulic efficiency of the turbine, $\rho$ is the density of water $\left(\mathrm{kg} / \mathrm{m}^{3}\right), g$ is the acceleration due to gravity $\left(\mathrm{m} / \mathrm{s}^{2}\right), Q$ is the volume flow rate passing through the turbine $\left(\mathrm{m}^{3} / \mathrm{s}\right)$, and $h$ is the effective pressure head of water at the turbine $(m)$. The best turbines can have hydraulic efficiencies in the range $80 \%$ to $90 \%$ (higher than most other prime movers). Figure 1 illustrates a typical RoR small hydro scheme [3].

In a typical small hydro power scheme, water is diverted from the river through an intake weir. The water passes through a desilting tank in which the water is slowed down sufficiently for suspended particles to settle down before descending to the turbine. In RoR installations, water is carried to the forebay by a canal. A pressure pipe, known as a penstock, conveys the water from the forebay to the turbine [4,5].

In India, small hydro schemes are classified as follows [1,2]:

\begin{tabular}{lc}
\hline Class & Station Capacity \\
\hline Micro & upto $100 \mathrm{~kW}$ \\
Mini & $101 \mathrm{~kW}$ to $2000 \mathrm{~kW}$ \\
Small & $2001 \mathrm{~kW}$ to $25000 \mathrm{~kW}$ \\
\hline
\end{tabular}

\section{Cost Estimation}

The basic components of small hydro scheme can be broadly classified as 1) civil works and 2) electromechanical equipments.

\subsection{Civil Works}

Civil works of small hydropower scheme comprise of following major components [6,7]:

1) Diversion weir and intake: required for diverting the flow of water from the river or stream towards the intake channel.

2) Intake channel: to convey water diverted from the weir.

3) Desilting tank: to remove silt to minimize erosion.

4) Forebay: provided at the end of water conductor with some storage capacity to fulfill immediate water demand on starting and to absorb water in case of sudden stoppage of generating unit.

5) Penstock: conduit carrying water from forebay to the turbine.

6) Spilling arrangement: the access flow that enters into the intake during flood or at part load needs to be spilled as early as possible.

7) Power house building is a simple structure housing the generating unit.

8) Tailrace channel to carry the water coming from the turbine and convey back to the flowing stream.

\subsection{Electro-Mechanical Equipment}

The electro-mechanical equipment are required to convert the available energy in flowing water into electrical energy, to control it and to transmit it to the power grid/ load points.

The major electro-mechanical components of power plant are the inlet valve, turbine, draft tube, gate, generator, control and protection equipment, Substation for evacuation of power. Turbines and generators are the major items in terms of cost and space requirement [6-8].

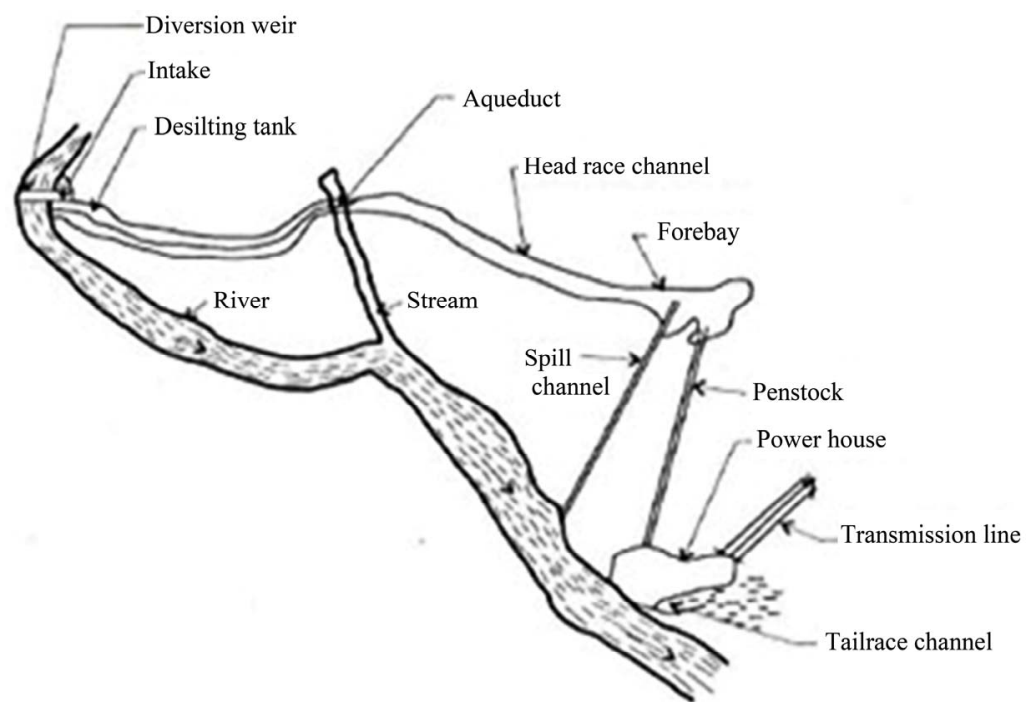

Figure 1. A typical layout of a SHP scheme. 


\section{Methodology for Cost Estimation}

The cost estimation process starts with the collection of data required for this purpose, which involves various components of civil works and electromechanical equipment of different projects, executed recently. The cost components are then adjusted considering inflation rates over the years. This data set is then screened to detect outliners which have unreasonable installation cost. The parameters on which the civil and E\&M cost depends are identified. These are installed capacity, head and year of commissioning, etc. The cost of the electromechanical equipment (turbine, alternator and regulator) is substantial in a small hydropower plant.

In the present, study an attempt has been made to develop the cost relationship for electro-mechanical equipment of SHP project using three different mathematical techniques. The cost correlations obtained from these techniques are than compared with the cost of actual existing power plant installed recently.

\subsection{Correlation through Sigma Software}

The expression of initial cost of electro-mechanical equipment is:

$$
\text { Cost, } C=a P^{b} H^{c}
$$

Applying logarithms in the of expression (2), it is obtained

$$
\log C=\log \left(a P^{b} H^{c}\right)=\log a+b \log P+c \log H
$$

Carrying out a variable change

$$
\begin{gathered}
Z=\log C \\
X=\log P \\
Y=\log H
\end{gathered}
$$

Expression (3) will remain the following way

$$
Z=\log a+b X+c Y
$$

Substituting data of cost, power and head of every plant whose data are known in the previous expression, it is obtained

$$
\begin{gathered}
Z_{1}=\log a+b X_{1}+c Y_{1} \\
Z_{2}=\log a+b X_{2}+c Y_{2} \\
\vdots \\
Z_{n}=\log a+b X_{n}+c Y_{n}
\end{gathered}
$$

Then we proceeded to search the plane $A X+B Y+C Z+$ $D=0$ with the best fit to data $\left(X_{k}, Y_{k}, Z_{k}\right)$ and carrying out a multiple regression between the independent variables $(X, Y)$ and $(Z)$

$$
A X+B Y+C Z+D=0
$$

Working out the value of $Z$, supposing without restriction as the plane would not be vertical,

$$
Z=-\left(\frac{D}{C}\right)-\left(\frac{A}{C}\right) X-\left(\frac{B}{C}\right) Y
$$

Constants $a, b$ and $c$ are obtained by comparing Equations (4) and (7) through the following expressions:

$$
\begin{aligned}
& a=e^{-\frac{D}{C}} \\
& b=-\frac{A}{C} \\
& c=-\frac{B}{C}
\end{aligned}
$$

The function of cost will be

$$
\text { Cost, } C=a P^{b} H^{c}
$$

The cost function has been developed which is sensitive to the installed capacity and head parameters. The exponents for these parameters have been obtained by regression analysis. In the first step, analysis is done between installation cost and head to find out the exponent of head. Then in second step results were analysed with the installed capacity to find out the coefficient and exponent of installed capacity. The developed corelation is as given by Equation (10) [9].

$$
C=6.882 H^{-0.0782} P^{0.6369}
$$

\subsection{Correlation through Linest Method}

This method calculates the statistics for a line by using the "least squares" method to calculate a straight line that best fits the data, and then returns an array that describes the line. LINEST [MS office excel - 2007] can also be combined with other functions to calculate the statistics for other types of models that are linear in the unknown parameters, including polynomial, logarithmic, exponential, and power series. Because this function returns an array of values, it must be entered as an array formula.

The equation for the line is:

$$
\begin{gathered}
y=m x+b \quad \text { or } \\
y=m_{1} x_{1}+m_{2} x_{2}+\ldots+b \text { (if there are multiple ranges of } \\
x \text {-values) }
\end{gathered}
$$

where the dependent $y$-value is a function of the independent $x$-values. The $m$-values are coefficients corresponding to each $x$-value, and $\mathrm{b}$ is a constant value. Note that $y, x$, and $m$ can be vectors. The array that LINEST returns is $\left\{m_{n}, m_{n-1} \ldots m_{1}, b\right\}$. LINEST can also return additional regression statistics. The developed corelation is as given by Equation (13).

$$
C=0.136391 P-1.73409 H+524.9
$$

\subsection{Correlation through Logest Method}

This method, calculates an exponential curve that fits the 
data and returns an array of values that describing the curve. Because this function returns an array of values, it must be entered as an array formula.

The equation for the curve is:

$$
\begin{gathered}
y=b \times m^{x} \text { or } \\
y=\left(b \times\left(m_{1}^{x_{1}}\right) \times\left(m_{2}^{x_{2}}\right) \times \cdots\right) \text { (if there are multiple } \\
x \text {-values) }
\end{gathered}
$$

where the dependent $y$-value is a function of the independent $x$-values. The $m$-values are bases corresponding to each exponent $x$-value, and $\mathrm{b}$ is a constant value. Note that $y, x$, and $m$ can be vectors. The array that LOGEST [MS office excel - 2007] returns is $\left\{m_{n}, m_{n-1}, \cdots, m_{1}, b\right\}$. The developed corelation is as given by Equation (16).

$$
C=664.072(1.00011)^{P}(0.99865)^{H}
$$

\section{Results and Discussions}

The cost data of electro-mechanical equipment from different existing sites and the manufacturers were collected and adjusted accordingly considering the inflation over the years. These cost data were used to develop the correlations. The results obtained from these correlations were verified from the cost data of electro-mechanical equipment of the newly installed SHP projects.

Figure 2 shows the error analysis between the actual cost and the analyzed cost of electro-mechanical equipment of small hydropower plant using the correlation obtained from the sigma plot software. Overall the data obtained from the mathematical model are very much close to the actual data with a maximum error of $\pm 10 \%$.

Figure 3 shows the error analysis between the actual cost and the analyzed cost of electro-mechanical equipment of small hydropower plant using the correlation obtained from the Linest method. Overall the data obtained from the mathematical model are very much close to the actual data with a maximum error of $\pm 5 \%$.

Figure 4 shows the error analysis between the actual cost and the analyzed cost of electro-mechanical equipment of small hydropower plant using the correlation obtained from the Logest method. Overall the data obtained from the mathematical model are very much close to the actual data with a maximum error of $\pm 18 \%$.

Figure 5 shows the comparison of cost obtained from three different mathematical models and actual cost (as collected) for electro-mechanical equipment of different capacities at a fixed head of $120 \mathrm{~m}$. The cost obtained from the mathematical model obtained from sigma plot and Linest method are closes to the actual cost of electromechanical equipment and can be used for prediction of the cost such equipment.

\section{Conclusions}

In the present study, an attempt has been made to develop a methodology for determination of the cost of electro-mechanical equipment based on cost influencing parameters i.e. head and capacity. Mathematical models were developed using three different methods and the results obtained from these models were compared with actual cost data as obtained from the recently developed projects. The results obtained from these mathematical models show the percentage of error. It is seen that the

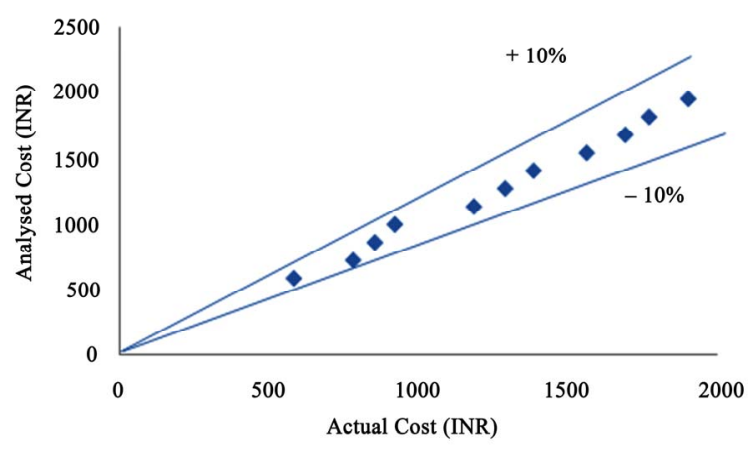

Figure 2. Error analysis of analyzed cost and actual project cost using sigma plot method.

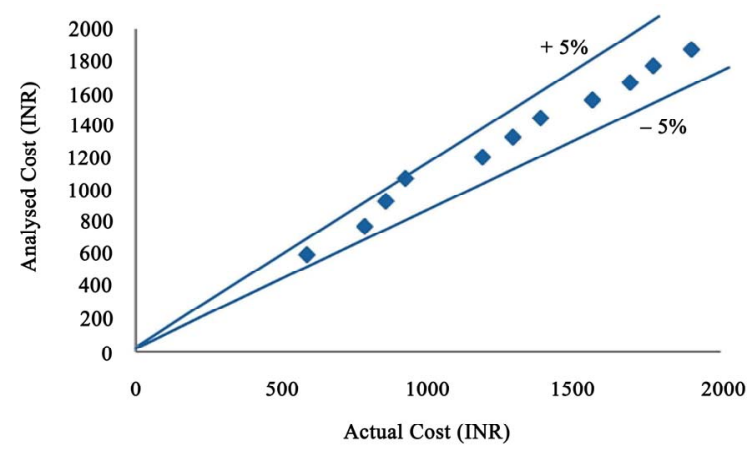

Figure 3. Error analysis of analyzed cost and actual project cost using linest method.

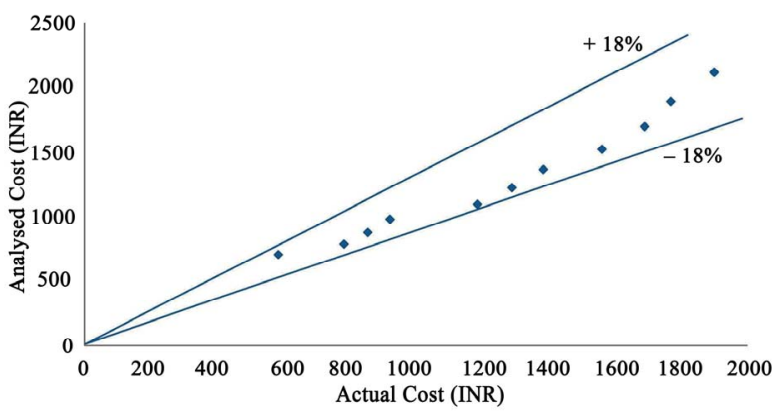

Figure 4. Error analysis of analyzed cost and actual project cost using logest method. 


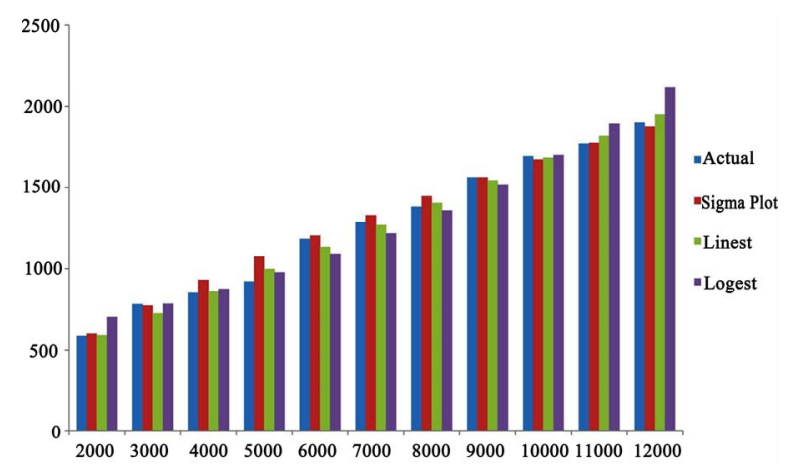

Figure 5. Comparison of different mathematical models to that of actual cost.

cost obtained from the mathematical model by using sigma plot and Linest method are very close to the actual cost of electro-mechanical equipment and can be used for the prediction of such cost for planning purpose.

\section{Acknowledgements}

The authors greatly acknowledge the financial support from Ministry of Human Resource Development, Government of India in the form of research scholarship to carry out this work.

\section{REFERENCES}

[1] "Guidelines for Development of Small Hydro Electric Scheme,” CEA, Government of India, New Delhi, 1982.

[2] B. S. K. Naidu, "Small Hydro," NPTI Publication, Faridabad, 2005.
[3] P. S. Nigam, "Hand Book of Hydro Electric Engineering,” Nem Chand and Brothers, Roorkee, 1985.

[4] J. S. Anagnostopoulos and D. E. Papantonis, "Optimal Sizing of a Run-of-River Small Hydropower Plant,” Energy Conversion and Management, Vol. 48, No. 10, 2007, pp. 2663-2670. doi:10.1016/j.enconman.2007.04.016

[5] S. K. Singal and R. P. Saini, "Analytical Approach for Cost Estimation of Low Head Small Hydro Power Schemes," Proceedings of International Conference on Small Hydropower, Sri Lanka, 22-24 October 2007, pp. 1-6.

[6] B. Ogayar and P. G. Vidal, "Cost Determination of the Electro-Mechanical Equipment of a Small Hydro-Power Plant," Journal of Renewable Energy, Vol. 34, No. 1, 2009, pp. 6-13. doi:10.1016/j.renene.2008.04.039

[7] S. K. Singal, R. P. Saini and C. S. Raghuvanshi, "Analysis for Cost Estimation of Low Head Run-of-River Small Hydropower Scheme,” Journal of Energy for Sustainable Development, Vol. 14, No. 2, 2010, pp. 117-126.

[8] G. A. Aggidis, E. Luchinskaya, R. Rothschild and D. C. Howard, "The Costs of Small-Scale Hydro Power Production: Impact on the Development of Existing Potential,” Journal of Renewable Energy, Vol. 35, No. 12, 2010, pp. 2632-2638. doi:10.1016/j.renene.2010.04.008

[9] S. Mishra, S. K. Singal and D. K. Khatod, "Costing of Small Hydropower Projects," Proceedings of International Conference on Prudent Development and Renewable Energy Resources, Chennai, 19-20 February 2011, pp. 22-25. 